\title{
IT Service and Support: What To Do With Geographically Distributed Teams?
}

\author{
Albert S. M. Tay \\ Idaho State University, Pocatello, Idaho, USA
}

taysion@isu.edu

\begin{abstract}
Organizations relied on geographically distributed teams to manage all functional aspects of their business. Two different firms that were successfully providing IT support for such complex environments were studied. The two case studies made it apparent that team cohesion, well-defined group norms, and effective feedback contributed to the firms' abilities to provide effective IT support in a culturally diverse and distributed environment. The concept of a team was challenged and re-defined to include additional players. In addition, factors related to outsourcing, staff burnout, and the shortage of IT professionals were discussed. This study aimed to increase our understanding of current work practices in distributed teams. Managers and human resource professionals as well as team leaders who supported the distributed teams can use the results of this investigation to develop implementation strategies and interventions for individuals, teams, and organizations to attract and retain their manpower.
\end{abstract}

Keywords: Geographically distributed teams, Intervention

\section{Introduction}

The Bureau of Labor Statistics of the United States Department of Labor recently revised the employment projections for the years 2008 to 2018. "The projections show an aging and more racially and ethnically diverse labor force, and employment growth in service-providing industries. More than half of the new jobs will be in professional and related occupations and service occupations." Among the ten industries with the largest wage and salary employment growth were: i) Management, scientific and technical consulting services, and ii) Computer systems design and related services (Bureau of Labor Statistics, 2009).

The labor force is predicted to be more diverse with the share of the labor force held by minorities projected to increase significantly. These professional and business services also implied that people would be working in a more geographically distributed and culturally diverse environment.

Material published as part of this publication, either on-line or in print, is copyrighted by the Informing Science Institute. Permission to make digital or paper copy of part or all of these works for personal or classroom use is granted without fee provided that the copies are not made or distributed for profit or commercial advantage AND that copies 1) bear this notice in full and 2) give the full citation on the first page. It is permissible to abstract these works so long as credit is given. To copy in all other cases or to republish or to post on a server or to redistribute to lists requires specific permission and payment of a fee. Contact 0HPublisher@InformingScience.org to request redistribution permission.
Colleagues no longer have to be working side by side. Some workers may not have met their colleague face-to-face, even though they may have communicated via email, telephone or videoconference. In addition, the colleague may come from a different cultural background. Managing this particular type of organizational structure required a different form of leadership. 
There had been an increasing amount of research and literature focused on distributed teams and effectiveness of virtual teams (Ahuja \& Carley, 1998; Dube \& Pare, 2001; Lipnack \& Stamps, 1997, 2000; Maznevski \& Chudoba, 2000; Montoya-Weiss, Massey, \& Song, 2001; Ramesh \& Dennis, 2002). Such studies provided insights on team development processes but these studies often use ad-hoc student groups in laboratory settings rather than examining existing teams in organizations (Powell, Piccoli, \& Ives, 2004).

Utilizing a case study approach, we are exploring the organizational environmental factors that contribute to a successful distributed IT support organization. The IT support organizations in two corporations from different industries were studied over a period of 26 months.

In this research, we examined the nature of distributed teams in multi-national corporations (MNCs) and factors that influenced their effectiveness. This study aimed to increase our understanding of current work practices in distributed teams. Managers and human resource professionals as well as team leaders who support the distributed teams can use the results of this investigation to develop implementation strategies and interventions for individuals, teams, and organizations to attract and retain their manpower.

\section{Literature Review}

\section{Teams}

Research on group and team processes had examined the influence of groups on individuals, individuals on groups (e.g., leadership studies), group conflict, group communications, and so on. The influence of the "embedding context" of groups and group development and evolution over time had received far less attention (Arrow, McGrath, \& Berdahl, 2000). However, a theoretical perspective on groups was now emerging in social psychology and management studies which viewed groups as "complex, adaptive, dynamic systems ... embedded in a hierarchy of levels and characterized by multiple, bi-directional, and nonlinear causal relations ... [that] developed as systems over time, and change as a function of changing conditions over time" (Arrow et al., 2000). This approach to understanding teams focused on group processes through which a group adapted and changed as context changed, and on the context in which groups operated. Such considerations were particularly relevant to teams transitioning to or operating in a global context.

A complex distributed organizational structure enabled by IT inherently required a correspondingly complex group effort to maintain continual IT services. Team development research had produced a number of models representing organizational, group, and process level dimensions to assess group effectiveness.

Building on group process models as represented by McGrath (1984), McGrath and Altman (1966), Hackman (1987), and Gladstein (1984), Sundstrom, De Meuse, and Futrell (1990) proposed an 'Ecological Framework' for team development and effectiveness within an organizational complex (Figure 1). This framework served as a lens to assess the effectiveness of IT support in complex MNCs.

Sundstrom, De Meuse, and Futrell's (1990) ecological framework depicted work team effectiveness as dynamically interrelated with organizational context, boundaries, and team development and assumed that work teams can best be understood in relation to external surroundings and internal processes.

Team effectiveness was both influenced by and influences the organizational context, the team's boundaries, and the development of the team. Team effectiveness had two dimensions namely: Performance and Viability. Team effectiveness can thus be defined as the acceptability of the team's output to stakeholders and the ongoing existence of the team. Organizational context fac- 


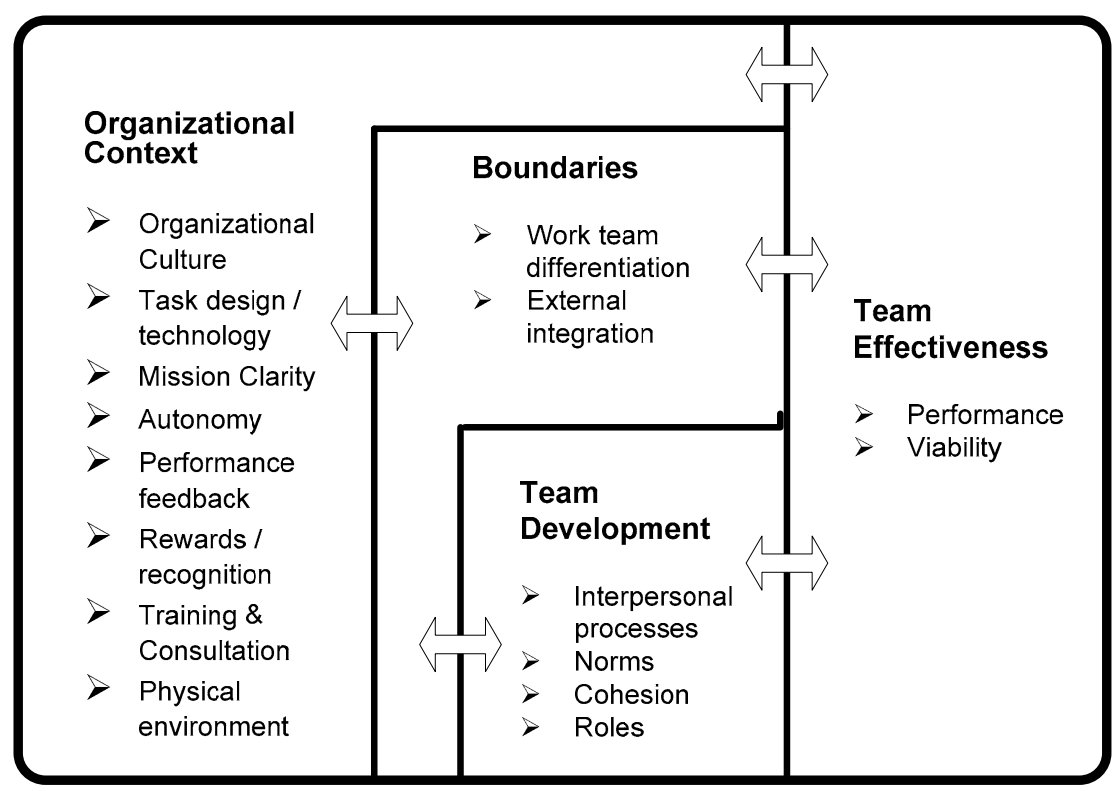

Figure 1: Sundstrom, De Meuse, and Futrell's (1990) Ecological Framework

tors like reward and recognition, autonomy and training can augment team effectiveness by providing resources needed for performance. The boundaries were a means of differentiating a work unit from others and defining how the group needed to operate within its context to be effective. Teams change and develop new ways of operating as they adapt to their context. Team development includes group structure like norms and roles, as well as interpersonal processes. The adjacent facets of the framework had reciprocal interdependencies; for example, boundaries influence team effectiveness that in turn alters the boundaries.

\section{IT Support}

In IT, support referred to the personal assistance vendors and internal personnel provide to technicians and end users concerning hardware, operating systems, and programs (http://whatis.techtarget.com/definition/0, sid9 gci774434,00.html). Nelson, Nadkarni, Narayanan, and Ghods (2000, p. 476) describe software operations support to include the "activities included in the IEEE (1990) definition of software maintenance, but also encompasses activities such as evaluating user business processes for opportunities, assisting users with new or modified requirements, and ongoing platform or technology changes." IT departments in large organizations often had to implement and maintain computer and infrastructure equipment that would permit the smooth operation of the application software.

\section{Proximity and IT Support}

IT development and support was a complex social process that was communication and coordination intensive and when scaled to global dimensions, the complexity was magnified many times over (Carmel \& Agarwal, 2001). When people were no longer co-located, direct observation and face-to-face conversation were difficult or impossible, posing problems for teams trying to work together. Furthermore, the cost of getting distributed team members together also increased (Kiesler \& Cummings, 2002). A geographically distributed team was defined as a group of people who work interdependently with a shared purpose across space, time, and organization boundaries (Lipnack \& Stamps, 2000). In the most extreme case, the team members are scattered in offices in different parts of the world. 
An organizational unit such as IT support cannot function without coordination and control; unfortunately, distance created difficulties in both. Coordination often required intense and ongoing communication (Ramesh \& Dennis, 2002). Controls can be formal (such as budgets and explicit guidelines) or informal (such as peer pressure). It was recognized that for knowledge workers, coordination and control had in many ways blended together.

\section{Outsourcing}

Another trend in IT support was outsourcing of various functions to IT firms, and "offshoring" (i.e., the relocation to foreign countries) of outsourced activities to low-cost companies. Although offering various financial benefits, these changes may also complicate the IT support coordination and communication processes.

The outsourcing literature discussed the risks and benefits associated with outsourcing, the structuring or anatomy of outsourcing contracts, how to manage the outsourcing relationship, and the impact on host countries and the implications for home countries (Ang \& Straub, 1996; Barthelemy, 2001; DeBow, 1994). However, little had been said about the impact of the outsourcing on the organizational structure and nature of work.

\section{Research Methods}

This research used an organizational case study design because case study is a suitable strategy for doing qualitative social science research that leads to understanding complex social phenomena (Stake, 1995; Yin, 2002). Case studies allowed for fieldwork that "retains holistic and meaningful characteristics of real-life events" (Yin, 1994). A goal of casework was to observe the details of interaction in a particular, complex single situation (Stake, 1995).

A case study approach provided a method for learning about a complex instance, based on a comprehensive understanding of that instance obtained by extensive description and analysis of that instance taken as a whole and in its context (GAO, 1990). Patton (1990) proposed that case studies were particularly useful in studying a process and notes, "Quality inquiry is highly appropriate in studying processing because depicting process requires detailed description." This led to application of both inductive and deductive methods to help direct data analysis - a strength of case study research (Lee, 1989). Case study data, though not generalizable to a population of organizations, can be helpful to generalize empirical findings in one setting to theoretical concepts and processes, which may be tested in other settings (Lee \& Baskerville, 2003).

\section{Data Collection}

In this study, three data collection methods were employed - semi-structured interviews, observation and analysis of business documents were conducted over a period of 26 months for the two organizations to create rich descriptions. Documents and newspaper and journal electronic databases were reviewed before and after the interviews to provide background information and new developments for the two organizations. Prolonged involvement with individual team members through less formal phone conversations and e-mails also enriched the experience. The researcher spent a significant amount of time to become familiar with the structure, language and history of the corporation and the team, and to allow research site participants to become familiar with the researchers prior to the first semi-structured interview. These preliminary meetings provided background and context for the study and helped the researcher finalize the interview questions related to distributed IT support within a global corporate environment.

All the participants agreed to have the interviews recorded. After each interview, notes of the interview were typed and the recorded interviews were transcribed as soon as possible. Documentary evidence for this study, both in electronic and paper form was collected. Data collected dur- 
ing interviews and from observations were checked against documentary evidence (printed and electronic) and vice versa, thus enhancing the credibility of findings by acting as a source for triangulation (Lincoln \& Guba, 1985).

A total of 30 staff from the two organizations participated in the interviews. Tables 1 and 2 show the breakdown of the number of participants and participants by location. Table 3 shows the breakdown of the participants by job titles. Five of the participants in the research were not from the IT department. The managers were interviewed initially and they made recommendations of staff to be interviewed. These staff in turn recommended other staff to participate in the research. Some of the staffs were interviewed more than once.

Table 1: Interviews

\begin{tabular}{|l|c|c|}
\hline Organization & Case 1 & Case 2 \\
\hline Industry & Hospitality & Transportation \\
\hline $\begin{array}{l}\text { No. of Employees } \\
\text { Interviewed }\end{array}$ & 14 & 16 \\
\hline
\end{tabular}

Table 2: Participants Breakdown by Locations

\begin{tabular}{|l|c|c|}
\hline Participants & Case 1 & Case 2 \\
\hline Hawaii-based & 13 & 4 \\
\hline Non-Hawaii-based & 1 & 12 \\
\hline Total & $\mathbf{1 4}$ & $\mathbf{1 6}$ \\
\hline
\end{tabular}

Table 3: Participants Breakdown by Job Title

\begin{tabular}{|c|c|c|}
\hline Participants & Case 1 & Case 2 \\
\hline $\begin{array}{l}\text { Senior } \\
\text { Executive/ } \\
\text { Managers }\end{array}$ & $\begin{array}{l}\text { CIO } \\
\text { Director Corporate Systems } \\
\text { Vice President Property Technology } \\
\text { Director System Operations }\end{array}$ & $\begin{array}{l}\text { CIO (California) } \\
\text { Director Corporate Systems (California) } \\
\text { Director Telecommunication \& Database } \\
\quad \text { (California) } \\
\text { Director Application Development } \\
\end{array}$ \\
\hline End-user & $\begin{array}{l}\text { Director of Revenue Management } \\
\text { HR Director }\end{array}$ & 0 \\
\hline Helpdesk & $\begin{array}{l}\text { IT Manager Australia (Australia) } \\
\text { Manager System/Operations } \\
\text { Project Administrator }\end{array}$ & $\begin{array}{l}\text { Manager PC (California) } \\
\text { Senior System Analyst } \\
\text { IT Manager }\end{array}$ \\
\hline Communications & 0 & $\begin{array}{l}\text { Manager Telecommunication (California) } \\
\text { Senior Analyst Telecommunication } \\
\text { (California) }\end{array}$ \\
\hline $\begin{array}{l}\text { Analyst/ } \\
\text { programmer }\end{array}$ & $\begin{array}{l}\text { Manager Data Processing } \\
\text { Business Systems Analyst } \\
\text { Data Analyst }\end{array}$ & $\begin{array}{l}\text { Associate Director Application Development } \\
\text { (California) } \\
\text { Manager Application Development (Califor- } \\
\text { nia) } \\
\text { Manager Terminal Application }\end{array}$ \\
\hline Operations/DB & $\begin{array}{l}\text { Manager Systems \& Programming } \\
\text { Programmer/Analyst }\end{array}$ & $\begin{array}{l}\text { Manager Database (California) } \\
\text { Manager Liaison (California) } \\
\text { Senior System Analyst (California) }\end{array}$ \\
\hline Web & 0 & Webmaster (California) \\
\hline
\end{tabular}




\section{Case 1}

This organization was a full-service lodging and hospitality company in Hawaii managing over 50 properties with more than 13,000 rooms in Hawaii, Australia, Micronesia, Fiji, Tahiti and New Zealand. Its corporate offices were located in Oahu, Hawaii. It had centralized services - accounting, IT, finance, engineering, purchasing, and special projects - that supported all the properties on Oahu. These corporate departments work with the respective departments in each property.

Leading each property was the General Manager who had the overall responsibility of the property's profitability and room occupancy. The General Manager of the property reported to the corporate management team (see Figure 2). The IT department took care of all IT needs of all the properties located on Oahu, Hawaii. For properties outside of Oahu, Hawaii, the IT department was responsible for the initial set up of the IT infrastructure and negotiating the maintenance contract with the vendor. Subsequently the IT department took on a consultative role in the day-today IT operations of the remote properties.

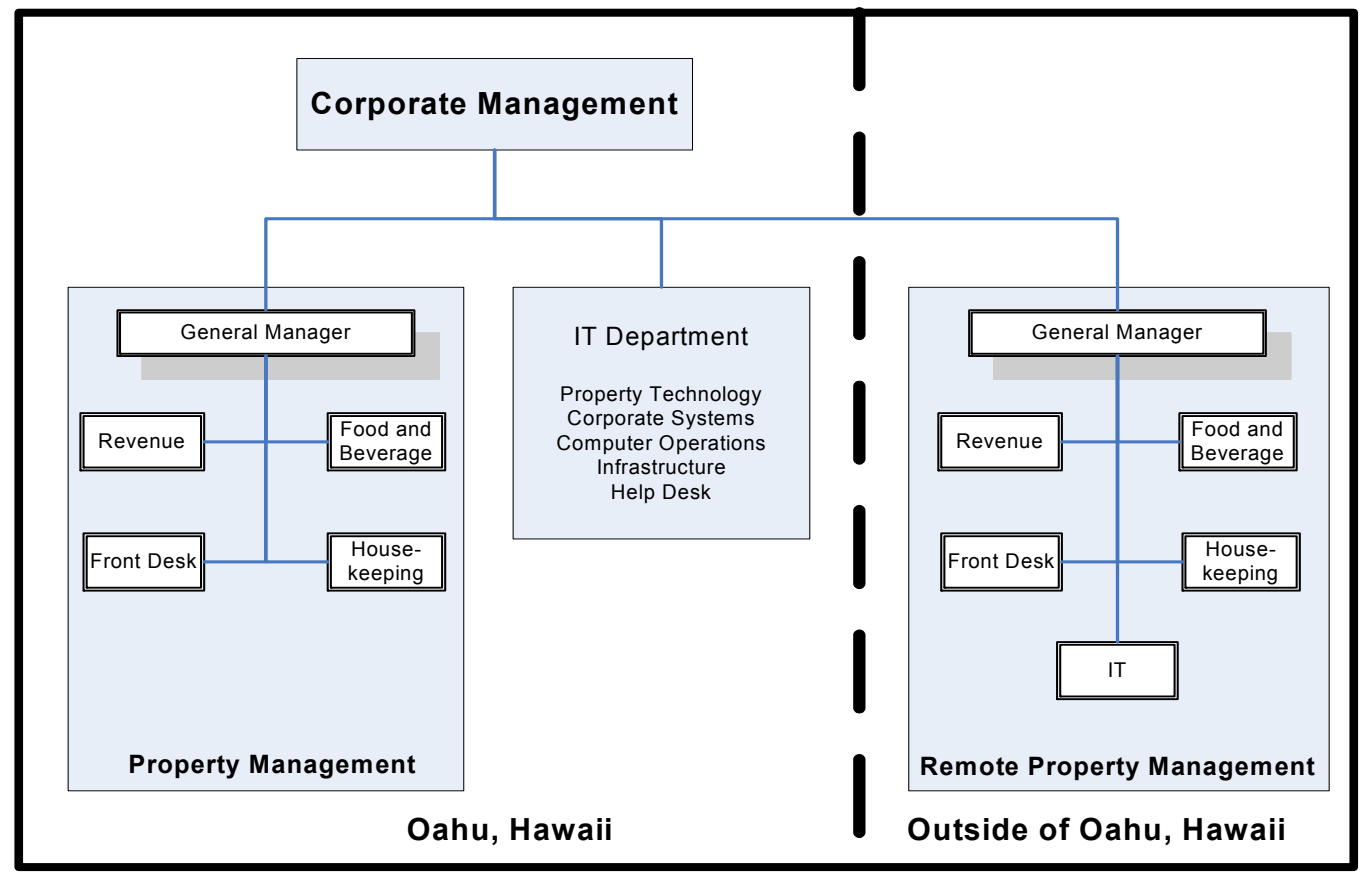

Figure 2: Case 1 Organizational Structure

\section{Case 2}

This organization was headquartered in California and a leading U.S. domestic shipping carrier offering customers a wide variety of transportation services between the West Coast and Hawaii, Guam, and Mid-Pacific. It was recognized for its industry-leading Customer Support Center and online services via the Internet, allowing customers to efficiently and effectively manage their shipment information.

It had a highly centralized organizational structure within a globally distributed environment. The remote offices reported directly to corporate management. The remote office IT department reported directly to the corporate IT group (see Figure 3).

The organization had recently re-aligned all IT services along business functions resulting in higher volume of coordination of business activities among the remote sites and headquarters. As 
a result, tightly coupled IT arrangements were needed for coordination of IT support as well as for business operations.

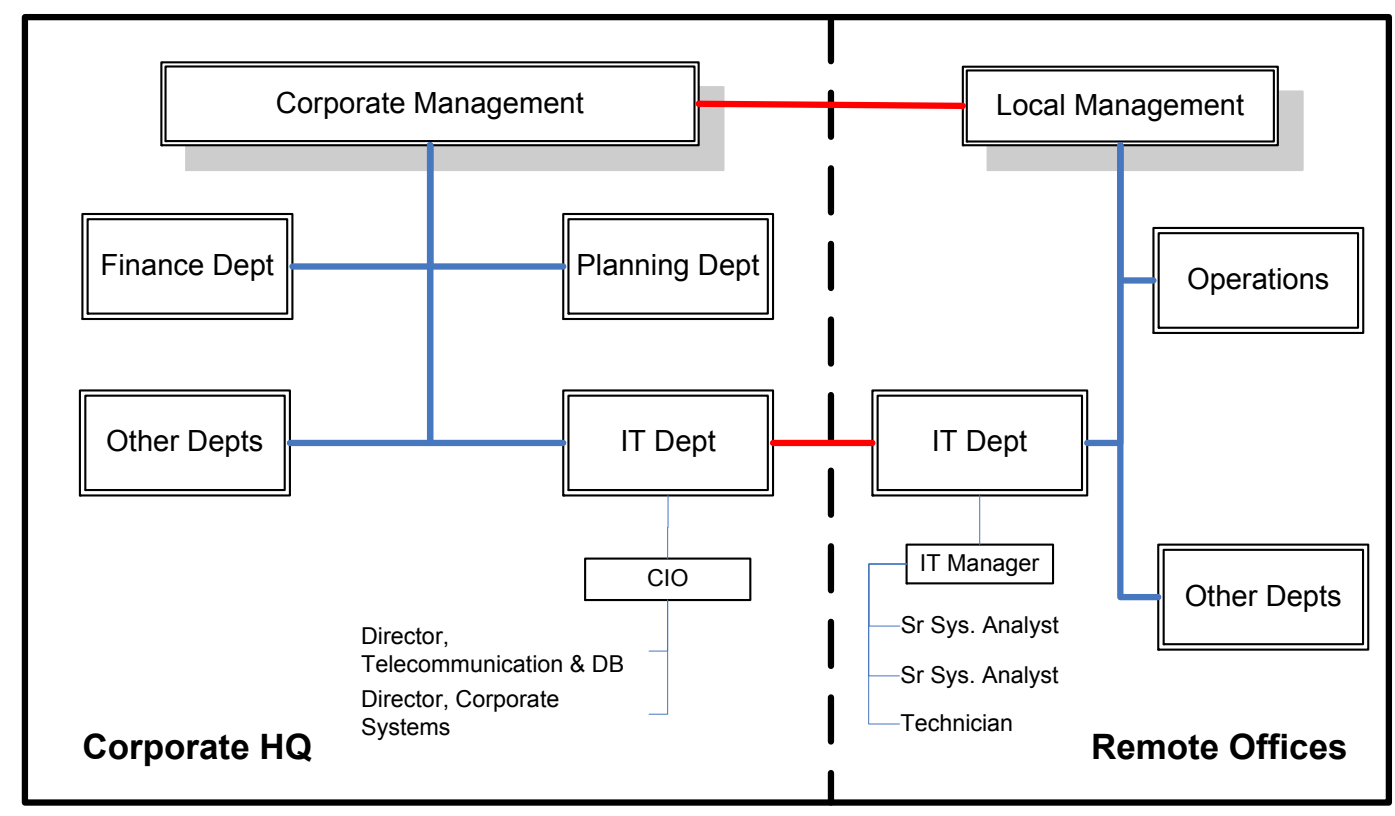

Figure 3: Case 2 Organizational Structure

Table 4 presents a summary of the characteristics and practices of the two case studies. Both organizations were similar in some ways and different in others. In both organizations, the organization structure was complex. Both were subsidiaries of a larger parent/holding company. Both organizations worked closely with other subsidiaries of their respective holding companies.

Table 4: Summary of Characteristics and Practices

\begin{tabular}{|c|c|c|}
\hline Category & Case 1 & Case 2 \\
\hline Organization & $\begin{array}{ll}\text { - } & \text { Highly Complex } \\
\text { - } & \text { Centralized Management } \\
\text { - } & \text { Medium to High Degree of } \\
& \text { Formalization } \\
\text { - } & \text { Tightly coupled } \\
\end{array}$ & $\begin{array}{ll}\text { - } & \text { Highly Complex } \\
\text { - } & \text { Centralized Management } \\
\text { - } & \text { Medium Degree of Formal- } \\
& \text { ization } \\
\text { - } & \text { Tightly coupled } \\
\end{array}$ \\
\hline Locations & $\begin{array}{l}\text { - Oahu, Oahu } \\
\text { - Other Hawaiian Islands } \\
\text { - Australia } \\
\text { - New Zealand } \\
\text { - Asia/Pacific }\end{array}$ & $\begin{array}{l}\text { - Terminals/ports in Hawaii } \\
\text { - Joint Ventures for termi- } \\
\text { nals/ports on the West Coast } \\
\text { - Guam } \\
\text { - Arizona - Office } \\
\text { - Utah - Office }\end{array}$ \\
\hline $\begin{array}{l}\text { Computer Operations and } \\
\text { support for ERP system }\end{array}$ & $\begin{array}{l}\text { In house - Oahu } \\
\text { Outsourced - Other Locations }\end{array}$ & Outsourced \\
\hline PC Hardware/Software & $\begin{array}{l}\text { In house - Oahu } \\
\text { Outsourced - Other Locations }\end{array}$ & In house \\
\hline Web Design & Outsourced & Outsourced \\
\hline
\end{tabular}




\section{Data Analysis}

The case study resulted in the collection of a significant amount of data in a variety of formats. The coding scheme used was adapted from the Sundstrom, et al., (1990) Ecological Framework. Utilizing key words and synonyms from the constructs of the ecological framework, the raw data (interview transcript and notes from observation and interviews) was reduced reiteratively. The raw data were also re-examined without using the a priori coding to discover if new categories existed. In both instances, several iterations of data coding were performed, adding and eliminating categories during subsequent passes through the data. Through this iterative process several broad areas emerged.

\section{Findings}

These two organizations presented above reflect how most MNCs were structured. There was often direct or dotted line reporting to supervisors who were located in different offices. This complex structure resulted in the heavy use of ICTs for communication and to coordinate activities.

\section{Organizational Context}

The significant areas that emerged from the data analysis would be discussed here focusing on . on "organizational culture" and "performance and feedback," which seemed particularly important in these two case studies.

\section{Organizational culture}

Management, through policies and procedures, often determined the organization culture of the organization. This in turn affected the relationship of the various business units/teams and the effectiveness of the individuals and departments.

Though the organizational structures differ, the organizational cultures of the two organizations were similar. They created an environment that promoted accountability and respect. The majority of the managers in the two organizations did not micromanage their staff. The managers do not look over the shoulders of the staff monitoring their every movement and actions. They gave the staff the autonomy to do their job. The managers often met with their personnel to disseminate information.

When things went wrong, managers were not quick to delegate blame to a subordinate. Instead, the manager shouldered the responsibility personally. This resulted in the staff developing a strong sense of camaraderie with the managers as well as trust among the team. The team relationship was strengthened and created an open and cooperative work environment. The Director of Corporate Systems spoke of the relationship and environment of the IT department at Case 1:

"I think we function really, really well with each other. We do have our arguments. It is almost like a family. I know that even if we get into an argument, when the chips are down, I can call [the Director of Systems Operations] and he will be there to help me. So we fight like regular people. That is kind of a good thing because we are quite vocal."

The top management at Case 1 had an interesting philosophy of encouraging their personnel to join other corporations and rejoin the corporation after a while. The top management felt that by leaving the organization, personnel learned from other corporations' operations and expanded the employee's knowledge and horizon. This philosophy fostered a high level of trust between management and the employees. The employees knew that their jobs would still be there if and when 
they returned to the organization. The CIO from case 1 was a good example. He left the corporation and worked for another organization for four years before re-joining the corporation.

\section{Performance and feedback}

Another important component in the Ecological Framework was performance and feedback. The IT departments used different sets of metrics to measure the performance of the IT support staff in addition to supervisors' evaluations. These metrics measured the performance of individual staff objectively and reduced any prejudice against the individual. This encouraged the staff to perform their best and developed trust in their supervisors. The Director of Corporate Systems in Case 2 described the IT support personnel in Hawaii as follows:

"They are very proud to work for the company. They take their job extremely seriously, extremely committed, work far beyond normal hours. Do whatever it takes and whenever it takes and are on call all the time. And everybody works outside of their original jobs."

When the IT support personnel were asked if they ever thought of leaving the organization, the Manager of Data Processing group within Case 1 replied, "I thought about leaving but decided to stick it out as I could not bear to part with my friends. They are like family to me. Furthermore the company has been very good to me and I like the company."

The organizations experienced IT employee turnover rate that was much lower than the national norm of $14.9 \%$ (voluntary) and 25.6\% (voluntary and involuntary) (Nobscot Corporation, n.d.).

The IT support personnel were very supportive of each other. The notice boards at the IT departments were plastered with Greetings Cards, IT personnel family pictures, and a variety of personal announcements. It was clear that in these two cases, the organizational context (particularly culture and performance feedback) helped developed more effective support staff, even in a distributed environment.

\section{Boundaries}

Team boundaries can be thought of as both the lines within, and the lines around a team. Teams had external boundaries that distinguished them from other teams and internal boundaries like geography, time zones, cultural and functional expertise (Espinoza, Cummings, Wilson, \& Pearce, 2003).

The company from case 2 had successfully outsourced their computer operations and had managed the relationship with the outsource partners very effectively. They maintained a skeleton team of IT members who were familiar with the business processes as well as the technical skills to work with the outsource vendor. They also used a set of metrics to measure the performance of the outsource vendor. When the vendors failed to meet or comply with the agreed upon performance level, the vendors would be penalized financially.

However, when the organization from case 1 tried to outsourced their IT operations under the previous CIO, it created a lot of unease as IT staff members were re-assigned to other business units/departments. The exercise was not successful as the outsource vendor's level of performance was unacceptable to the management team. The outsourcing experience left a bitter taste with the IT staff and even up to now, the IT staff would not discuss that episode. The outsourcing exercise failed largely owing to the hospitality industry's need to provide prompt personal services to their clientele.

The helpdesk technicians from case 1 were able to mobilize their contacts to assist in resolving issues near the contacts' workplace. These helpdesk technicians had formed relationships with these contacts when providing IT support previously. These contacts became the extended eyes 
and hands of the helpdesk technicians since the helpdesk technicians were centrally located. The team boundaries thus became blurred and no longer clearly identified.

\section{Team Development}

In case 1, Human Resources department conducted orientation for its new employees. The manager in charge of the new employee orientation at Case 1 shared that "the purpose of the training is to get the new employees acquainted with the values and beliefs of the organization but it is up to the individuals if they will embrace these values and beliefs and make it a part of their lives." The manager also mentions that employees in properties outside of Hawaii do not embrace the values like the employees in Hawaii.

During this orientation, the new employees met with the Chief Operating Officer and various department heads. The new employees were instructed on the various employment policies as well as the organization's values and beliefs.

The organization in case 2, however, did not have an extensive new employee orientation program like Hotel-Inc. The Director of Corporate Systems from Case 2 said that new employees were often "shown the ropes by the other staff" in the department. The organization, however, did have a stringent employment process. The potential staff go through a long probation period before being hired on a permanent basis. The IT supervisor in the Hawaii office, for example, worked with the organization for three years on a temporary basis before he was hired on a permanent basis. In this way, the organization Case 2 was able to evaluate the personnel and ensured that the new hire was a perfect match for the organization and the department and be able to work harmoniously with the existing personnel.

The IT support personnel in both organizations had worked in the organizations for a long period of time, especially those who worked in Hawaii. Some of the personnel had worked in other departments prior to joining the IT department. As a result, they had established a history of working with other personnel in various departments. They knew each other well and treated each other like family. Most of the IT support personnel had long tenure with the organizations compared to industry standards, some as long as 30 years.

Management created opportunities for personnel to socialized and interacted with one another. The Director of Corporate Systems from case 1 had a departmental lunch with all the personnel. During these lunches, they talked about all kind of things, both personal and about work. The organization from case 2 had pantries where staff could eat their lunch together. These were great opportunities for personnel to socialize with one another.

Through these socializations, members learned team norms, interpersonal processes and roles implicitly or explicitly.

\section{Implications}

\section{The Concept of Team}

The concept of 'team' as commonly understood in team research literature was called into question when teams were examined in the distributed environment context. Considering that most distributed team research had used artificially created, ad-hoc student teams (Powell et al., 2004). The ad-hoc student teams in these studies had clearly identified, defined boundaries and had strong perception of being part of the "team" may be an artifact of the research process rather than a reflection of organizational reality. In real-life organizations, it was not so clear who was on the team, and if teams were even needed or effective in IT support activities. The external and internal boundaries were not clearly identified. 
From the case studies, the players involved in providing a support event can and may include the organization's IT support staff, IT support staff from different location or office, employees from other department within the organization, and IT support staff from outsource vendors or suppliers. Figure 4 is a visual representation of the composition of a distributed team. In this distributed setting, the boundary of the team had to extend beyond the traditional external and internal boundaries that we had become so accustomed.

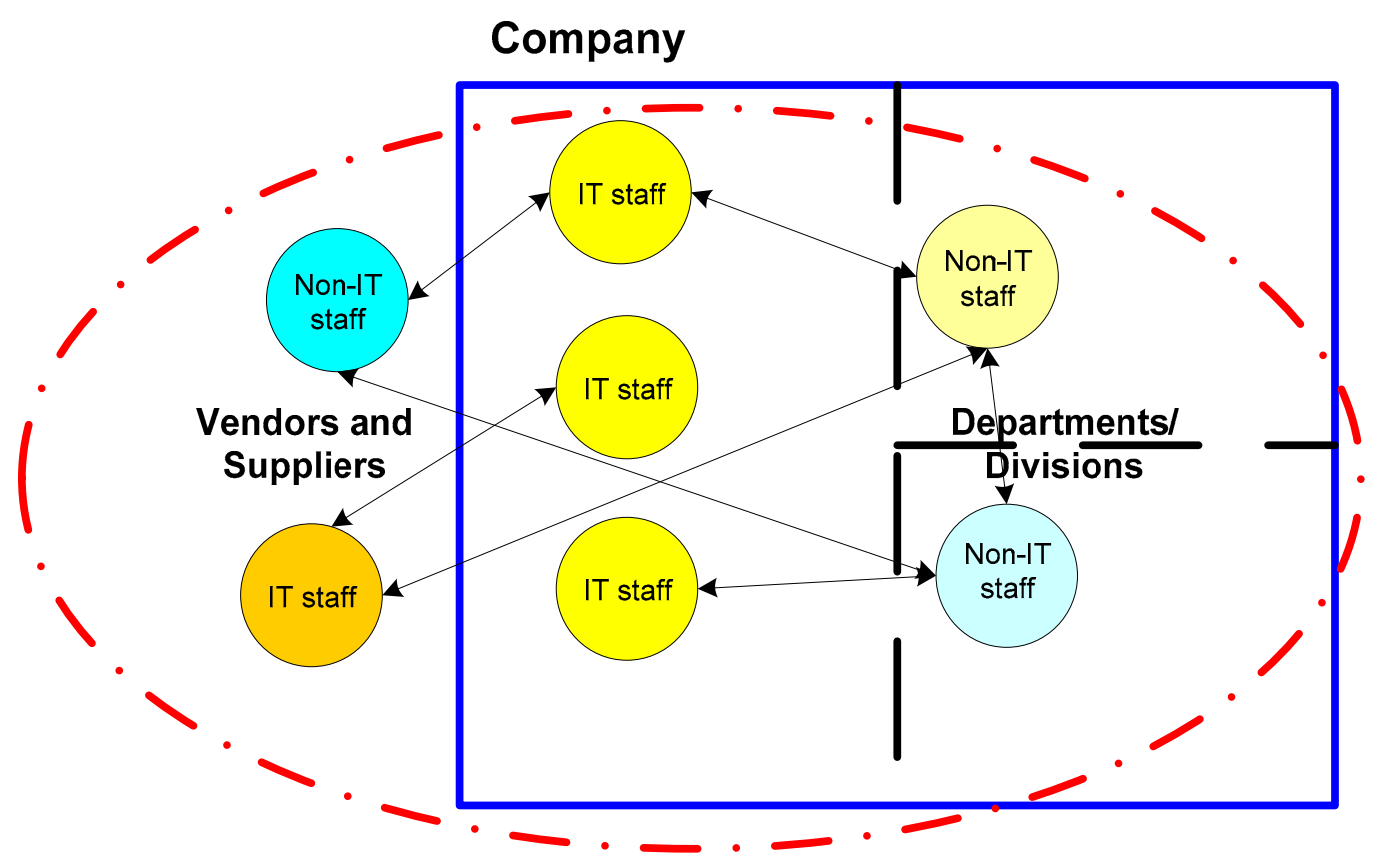

Figure 4: Composition and Communication Pattern of a Distributed Team

\section{Shortage of Skilled Manpower}

With the increasing use of IT in business, there was a great demand for IT professionals. The organization from case 1 had difficulty finding skilled IT professionals in Hawaii. As a result, it had re-trained its employees who had expressed an interest in becoming IT professionals. The organization also had to recruit IT professionals from out of state and internationally to fulfill their IT labor needs.

Managers and HR officers would have to be more creative when sourcing for personnel or the organization might resort to outsourcing a larger portion of the work to vendors if the organizations were unable to find the necessary labor. Re-training existing personnel who are interested is an alternative to solve work force needs.

\section{Management Skills}

With increasing use of outsource vendors to manage IT operations, IT professionals needed to take on more managerial tasks. The organization in case 2 outsourced its mainframe computer operations and retained a skeleton IT staff to manage the relationship with the outsource vendor. Making this business relationship work required an IT professional with strong managerial skills. The IT personnel would deal with the outsource vendor on a daily basis through their daily conference calls. 
Managers and HR officers need to improve the soft skills of these staff so that these staff could more effectively communicate with other people as well as managing the relationships with the outsource vendors and other business units. Personnel working in a distributed environment needed to have strong interpersonal communication skills and be a team player. Interpersonal communication referred to communication between individuals, often in a two person setting. Interpersonal communication skills encompassed all the behaviors and feelings that existed within all of us that influenced our interactions with others. Awareness of one's own character traits and bias as well as those of the other party would enhance communication and increase one's ability to mobilize the other party. Good interpersonal communication skills would help staff developed strong ties with other staff, suppliers and customers. In the two cases, the IT personnel possessed good interpersonal communication skills. They invested the time in building relationships with one another. IT support was essentially service oriented, and great people skills were crucial in their work.

\section{Burnt-out Syndrome}

HR officers had to monitor the number of hours the personnel worked. With ICTs, personnel are always contactable and therefore always at work though they may not be in the office. Personnel spent long hours at work and when they return home, they may be called upon to resolve issues remotely. The long hours would have undesirable effects on the personal lives of the personnel and result in unhappy home situations that might severely affect the productivity of the personnel. The IT support personnel in case 2 had Blackberry mobile smart phone (mobile devices that let them read and send emails) that made them always contactable. IT support work did not cease when the personnel left the office. A CNN news report ("Emails hurt IQ more than Pot," 2005) suggested that people are in danger of being caught up in a 24-hour 'always on' society.

Workforce members who engaged in long work hours each week may be increasing their risk for high blood pressure (Yang, Schnall, Jauregui, Su, \& Baker, 2006). In addition, "long work hours have increased mortality and have an impact on a number of adverse health condition ... and lead to disability retirement" (Yang et al., 2006. p. 748).

Organizations would have to monitor the welfare of their staff, especially those who work in a support role. Personnel who are unhappy and dissatisfied with their work or environment will tend to be less productive and will separate themselves from that organization eventually. This is costly to the organization in terms of lost productivity and recruitment cost. Paying attention to such details would minimize the cost to the organization and at the same time, it may secure the loyalty of the staff and improve the morale of the staff.

\section{Cultural Awareness}

HR officers and team managers would have to be cultural sensitive to the differences of the background of each member of the geographically distributed team. Culture combines visible and invisible things around us. The visible things are the products of cultural rules - the artifacts that surround us. The invisible, the sociofacts and mentifacts, include the laws, rules, regulations, norms, customs, and an immense number of other written and unwritten directions that guide and govern actions (Klopf \& McCroskey, 2007).

Members of the teams ought to be educated on cultural awareness. An increase in cultural awareness would reduce miscommunications among team members and increase shared meanings and beliefs. 


\section{Conclusion}

With the positive outlook of employment projection in the United States in the near future, MNCs will need to fulfill their labor force needs by drawing upon the labor resources from all available sources. MNCs will need to deal more effectively with their labor force who works in a geographically distributed team environment.

The IT support organizations from the two cases were effective as these organizations are still providing support to their respective organization. Using figure 1 to focus on the commonalities exhibited by the two organizations, the interplay between the different dimensions aids in understanding ways to achieve effective team outcomes in distributed team within multinational organizations. In particular, team viability, essentially the existence of the team as an ongoing unit was highlighted as one of the conditions of team effectiveness.

Team viability, in both organizations, was influenced by organizational culture, autonomy, performance feedback, and rewards. These dimensions also provided a foundation for the team development processes that occurred in organizations.

Cohesion within the group, combined with interpersonal processes, specifically open communications in combination with organizational tenure, helped facilitate group norms. Group norms were consistent with the organizational culture, and included respect for each other's roles.

In Figure 1, team effectiveness was represented as being an interplay between the organization, boundaries, and team development. This study highlighted the extension of external integration, both with other organizational departments and external suppliers, as a mediating component between the boundaries of work team differentiation and external integration.

\section{Limitations}

This study had both strengths and limitations. The strength of this research was that it involved intensive data gathering that informed our understanding of distributed IT support in natural settings. At the same time, such an approach raises questions of generalizability to other organiza-

tions. This study indicated that the case sites selected do highlight some research issues while not providing much insight into others.

Another limitation was that the investigation could be so all-encompassing that it was difficult to focus. Furthermore, it may be difficult to reconcile differences and assess how representative they are.

\section{Future Research Direction}

The two organizations provided an excellent environment to study distributed teams and at the same time presented some unique situations that would require further investigation. More studies need to be conducted to identify effective intervention methods for staff to reduce the "danger of being caught up in a 24-hour 'always on' society."

The phenomenon of the long tenure of the IT professionals in the Hawaii offices needed to be investigated. The IT professionals in Hawaii tend to remain with the same employer for a much longer period of time. A better understanding of this phenomenon would help organizations with their retention of IT professionals and in the long run reduced the organizations' costs incurred in the recruitment and training of new IT staff. 


\section{References}

Ahuja, M., \& Carley, K. (1998). Network structure in virtual organizations. Journal of Computer-mediated Communication, 3(4).

Ang, S., \& Straub, D. (1996). An economic analysis of IS outsourcing in U.S. banks [Working paper]. Nanyang Technological University and Georgia State University.

Arrow, H., McGrath, J. E., \& Berdahl, J. (2000). Small groups as complex systems: Formation coordination, development and adaptation. Thousand Oaks, CA: Sage Publications.

Barthelemy, J. (2001). The hidden cost of IT outsourcing. Sloan Management Review, 42(3), 60-69.

Bureau of Labor Statistics, United States Department of Labor. (2009). Employment projections - 2008-18. Retrieved 8 November, 2009 from http://www.bls.gov/news.release/ecopro.nr0.htm

Carmel, E., \& Agarwal, R. (2001). Tactical approaches for alleviating distance in global software development. IEEE Software, March/April, 22-29.

DeBow, Y. (1994). Anatomy of an outsourcing contract. Insurance \& Technology, 19(8), 16-17.

Dube, L., \& Pare, G. (2001). Global virtual teams. Communications of the ACM, 44(12), 71-73.

Emails hurt IQ More than Pot. (2005, April 5). Retrieved from http://www.cnn.com/2005/WORLD/europe/04/22/text.iq/index.html

Espinoza, J. A., Cummings, J. N., Wilson, J. M., \& Pearce, B. M. (2003). Team boundary issues across multiple global firms. Journal of Management Information Systems, 19(4), 157-190.

GAO. (1990). Content analysis: A methodology for structuring and analyzing written material (GAO Transfer paper 10.1.3). Gaithersburg, MD: US General Account Office.

Gladstein, D. L. (1984). Groups in context: A model of task group effectiveness. Administrative Science Quarterly, 29, 499-517.

Hackman, J. R. (1987). The design of work teams. In J. W. Lorsch (Ed.), Handbook of organizational behavior (pp. 315-342). Englewood Cliffs, NJ: Prentice-Hall.

IEEE Standard 610.12-1990. (1990). Glossary of software engineering terminology. Los Alamitos, CA: IEEE Computer Society Press.

Kiesler, S., \& Cummings, J. (2002). What do we know about proximity and distance in work groups? A legacy of research. In P. Hinds \& S. Kiesler (Eds.), Distributed work. Cambridge, Massachusetts: The MIT Press.

Klopf, D. W., \& McCroskey, J. (2007). Intercultural communication encounters. Boston, MA: Allyn \& Bacon.

Lee, A. S. (1989). A scientific methodology for MIS case studies. MIS Quarterly, 14(1), 33-50.

Lee, A. S., \& Baskerville, R. (2003). Generalizing generalizability in information systems research. Information Systems Research, 14(3), 221-243.

Lincoln, Y., \& Guba, E. (1985). Naturalistic inquiry. Beverly Hills, CA: Sage Publications.

Lipnack, J., \& Stamps, J. (1997). Virtual teams: Reaching across space, time and organizations with technology. New York: Wiley.

Lipnack, J., \& Stamps, J. (2000). Virtual teams: People working across boundaries with technology. New York: Wiley.

Maznevski, M., \& Chudoba, K. (2000). Bridging space over time: Global virtual team dynamics and effectiveness. Organization Science, 11(5), 473-492.

McGrath, J. E. (1984). Groups: Interaction and Performance. Englewood Cliffs, NJ: Prentice Hall. 
McGrath, J. E., \& Altman, I. (1966). Small group research: A synthesis and critique of the field. New York: Holt Rinehart \& Winston.

Montoya-Weiss, M., Massey, A., \& Song, M. (2001). Getting it together: Temporal coordination and conflict management in global virtual teams. Academy of Management Journal, 44(6), 1251-1262.

Nelson, K., Nadkarni, S., Narayanan, V., \& Ghods, M. (2000). Understanding software operations support expertise: A revealed causal mapping approach. MIS Quarterly, 24(3), 475-507.

Nobscot Corporation. (n.d.) US annual employee total separation rates by industry and by geographic region. Appendix F. Retrieved from http://www.nobscot.com/survey/us_total_separations_0804.cfm

Patton, M. (1990). Qualitative research and evaluation methods. Newbury Park, CA: Sage Publications.

Powell, A., Piccoli, G., \& Ives, B. (2004). Virtual teams: A review of current literature and directions for future research. The DataBase for Advances in Information Systems, 35(1), 6-36.

Ramesh, V., \& Dennis, A. (2002). The object-oriented team: Lessons for virtual teams from global software development. 35th HICSS, Hawaii.

Stake, R. E. (1995). The art of case study research. Thousand Oaks, CA: Sage Publications.

Sundstrom, E., De Meuse, K., \& Futrell, D. (1990). Work teams: Applications and effectiveness. American Psychologist, 45(2), 120-133.

Yang, H., Schnall, P., Jauregui, M., Su, T., \& Baker, D. (2006). Work hours and self-reported hypertension among working people in California. Hypertension, 48(4), 744-750.

Yin, R. (1994). Case study research: Design and methods (2nd ed.). Thousand Oaks, CA: Sage Publications.

Yin, R. (2002). Case study research: Design and methods (3rd ed.). Thousand Oaks, CA: Sage Publications.

\section{Biography}

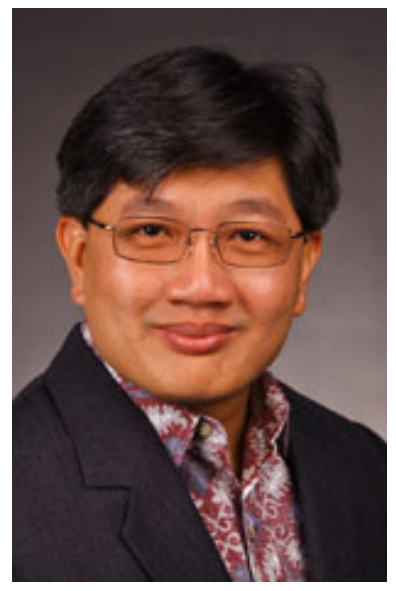

Dr. Albert Tay is an Assistant Professor of Computer Information Systems at Idaho State University. His areas of research interest include Global Information Systems, Organizational Impact of IT, Software Development and Support, and Technology Adoption. He has a BS in Information Systems from Brigham Young University-Hawaii (1992), a MS in Decision and Information Systems from Arizona State University (1993), and a PhD in Communication and Information Sciences from University of Hawaii at Manoa (2006). Albert has over six years of IT management experience with organizations such as Adaptec Inc, Applied Materials Inc., and Koeneman Capital Management. 